\title{
PROGRAMA DE APOIO AOS PROFESSORES INICIANTES DA REDE MUNICIPAL DE ENSINO DE POÇOS DE CALDAS (PAPIN): AÇÃO DE INSERÇÃO DOCENTE
}

\author{
Ana Maria Brochado de Mendonça Chaves ${ }^{1}$ \\ Ligia Maria de M. Chaves Incrocci ${ }^{2}$ \\ Renata Christian de Oliveira Pamplin ${ }^{3}$
}

\section{INTRODUÇÃO}

As preocupações sobre os anos iniciais da docência têm sido objeto de assuntos recorrentes nas aulas de graduação nos cursos de Pedagogia. Quase sempre as questões são abordadas pelos alunos que, a partir da observação e atuação docente realizadas nos estágios, constatam que há uma enorme diferença entre $\mathrm{o}$ ideal e o real. Como docentes, recorrentemente presenciamos as indagações dos futuros professores, que buscam nas reflexões na Universidade as "receitas" que poderiam, supõe-se, ao menos aliviar as expectativas de uma provável e próxima atuação docência.

Dessa forma, e buscando aprofundar nossos estudos sobre o tema "professores iniciantes", constatamos que ele tem sido objeto de pesquisa de inúmeros pesquisadores estrangeiros. Em comparação, o Brasil têm produzido poucas referências sobre a mesma temática ${ }^{4}$. Isso implica na dificuldade em refletir sobre o tema e suas complexidades durante a graduação, além de facilitar o denominado "choque com a realidade" que acontece no período de transição entre

\footnotetext{
${ }^{1}$ Universidade do Estado de Minas Gerais (UEMG) / Pontifícia Universidade Católica de Minas Gerais (PUCMinas Campus Poços de Caldas). Endereço eletrônico: ambmchaves1@uol.com.br

Doutoranda Universidade Federal de São Carlos (UFSCar). Endereço eletrônico: ligia.incrocci@gmail.com

3 Universidade do Estado de Minas Gerais (UEMG) / Faculdade Pitágoras (Poços de Caldas). Endereço eletrônico: renata.pampln@yahoo.com.br

${ }^{4}$ CHAVES, A. M. B. M. Impressões sobre o início da docência, seus contextos e a participação de licenciandas da Pedagogia no Programa Institucional de Bolsa de Iniciação à Docência (PIBID/CAPES). Tese (Doutorado em Educação). - Faculdade de Educação, Universidade de São Paulo, São Paulo, 2015.
} 
aluno-professor, podendo culminar não só no comprometimento do desenvolvimento profissional do professor iniciante, como no próprio abandono da docência.

Minimizar os impactos do início da docência é o objetivo principal das políticas de inserção do professor no contexto escolar. No Brasil, de acordo com Gatti, Barreto e André (2011, p. 35), "não há indicações de políticas por parte do Ministério de Educação dirigidas diretas e explicitamente a professores iniciantes. Alguns poucos estados e municípios tem se ocupado com a questão, mas a forma ainda é incipiente".

As autoras citam algumas experiências sobre a forma de entrada na carreira docente (notadamente os concursos) em três estados: Ceará, Espírito Santo e São Paulo. E também apresentam algumas ações formativas para professores iniciantes que acontecem nos município de Jundiaí (SP), Sobral (CE) e Campo Grande (MS), sendo que nestas últimas são políticas de secretarias municipais que se destacam, haja vista que apontam as possibilidades de intervenções dirigidas e com um acompanhamento contínuo junto aos professores iniciantes.

Neste sentido, e entendendo que a rede municipal de ensino de Poços de Caldas teve, entre os meses de agosto/2014 e abril/2015, o ingresso (nomeação) de 400 professores dos anos iniciais do ensino fundamental, sendo que dentre eles havia aproximadamente 60 professores que vivenciavam o início da docência, foi desenvolvido, no $2^{\circ}$ semestre de 2015, o Programa de apoio aos professores iniciantes da Rede Municipal de Ensino de Poços de Caldas (PAPIN).

Este teve por intuito proporcionar apoio pedagógico e profissional para a inserção docente iniciantes da rede municipal de ensino de Poços de Caldas, além de: a) criar iniciativa de formação continuada para docentes que são, em boa parte, egressos da UEMG / Curso de Pedagogia fora de sede, em Poços de Caldas; b) intensificar a interlocução entre Universidade e docentes de educação básica; c) promover o compartilhar de saberes e práticas docentes promovidos pela Universidade e escolas da educação básica.

\section{UMA QUESTÃO BÁSICA: A INSERÇÃO DAS PROFESSORAS INICIANTES NAS CULTURAS DOCENTES}

Dentre inúmeras dificuldades e desafios vivenciados no início da docência, aparece enquanto particularmente difícil a solidão dos professores 
iniciantes. Questão ressaltada em praticamente todos os estudos sobre professoras iniciantes e sua inserção nas culturas docentes. Ponto que é destacado na literatura, principalmente quando colocada a relação entre os professores iniciantes e os experientes.

Sem a completa aceitação dos pares e sem um acompanhamento por parte da direção ou supervisão pedagógica, suas vivências remetem a pesquisa de Cavaco (2000, p.163), na qual uma das professoras iniciantes, em Portugal, relata: "Nem me ouvem [professores experientes]. Só pouco a pouco vão vendo o que estou a fazer: não estimulam nada [...] Parece que já fizeram tudo, que já experimentaram tudo".

As expectativas de aceitação e acolhimento pelos pares às vezes demoram a ser cumpridas - mas sabemos que quase sempre o são, de uma maneira ou de outra. Knoblauch (2008, p. 26) considera, neste sentido, que "a escola socializa, por meio de sua cultura, todos aqueles que passam por ela". Ou seja, muitos professores sobrevivem - com ou sem arranhões, e constroem sua carreira profissional.

Reencontrar professores "desmotivados", coordenações ausentes diante de problemas de disciplina etc., se por um lado remetem as professoras iniciantes às lembranças desagradáveis, por outro fazem do início da sua docência, para várias delas, uma busca constante de superações, não só de dilemas e dificuldades na sala de aula, mas o próprio desafio de seu desenvolvimento profissional.

Inseridos em um contexto maior, no caso a escola, "as mudanças de crenças, de valores e de atitudes que ocorrem no corpo docente podem depender de mudanças prévias ou paralelas nas formas de os professores se relacionarem com os seus colegas" (HARGREAVES, 2001, p.187). Como afirmou Sarason (1982 citado por LIMA, 2003, p.35), alguns professores "estão psicologicamente sós, apesar de estarem num local densamente povoado".

Assim, Fontana (2000, p.113) descreve bem o que acontece com os professores iniciantes: "Com quem compartilhar as dificuldades encontradas na escola, quando um sentimento de 'fracasso profissional' vai se tornando público pelas interferências, pelos olhares e comentários da coordenadora pedagógica?". As professoras acompanhantes iniciantes participantes do PAPIN relataram sofrer esse constrangimento, presenciado por todos os envolvidos no programa. 
Outra situação vivenciada pelos professores iniciantes é a aprendizagem com os professores experientes através do "boca a boca", podendo acontecer quando eles pedem auxílio ou sofrem as reprimendas dos coordenadores (GUARNIERI; GIOVANNI, 2010).

O que notamos, por meio dos relatos das professoras iniciantes ao longo do PAPIN, foi mesmo a ausência de apoio das coordenações pedagógicas e dos professores experientes - assunto tratado em diversos estudos (FONTANA, 2000, GUARNIERI; GIOVANNI, 2010, MIZUKAMI, 1996). Conforme Fontana (2000, p. 68), "Embora ela [a escola] seja uma instituição social destinada ao ensino, não encontramos dentro dela quem nos ensine no próprio trabalho".

Refletindo sobre a questão acima, poderia se pensar na possibilidade de uma "partilha", no sentido de uma socialização dos saberes. Porém, para Hargreaves (2001, p.186), "o conceito normativo de partilha não é essencial nesta definição [culturas de ensino], pois a forma destas culturas pode ser individualista ou antagonista" ainda que, segundo $\mathrm{o}$ autor, as relações se modificam durante 0 desenvolvimento profissional dos professores. Dessa forma, "as culturas dos professores, as suas relações com seus colegas, figuram entre os aspectos mais significativos da sua vida e do seu trabalho." (HARGREAVES, 2001, p. 186).

Dentre esses aspectos, podemos citar, também, as culturas de ensino, que seriam reproduzidas pelos professores iniciantes a partir da aprendizagem com os professores experientes. O mesmo autor, referindo-se a essas culturas, explica:

[...] compreendem as crenças, valores, hábitos e formas assumidas de fazer as coisas em comunidades de professores que tiveram de lidar com exigências e constrangimentos semelhantes ao longo de muitos anos. A cultura transmite aos seus novos membros inexperientes as soluções historicamente geradas e colectivamente partilhadas de uma comunidade. Constitui, portanto, um enquadramento para a aprendizagem ocupacional. (HARGREAVES, 2001, p. 185-186)

As dificuldades e os desafios para o professores iniciantes são inúmeros e complexos, mas não devem ser naturalizados, ou seja, considerados dentro de uma inexorabilidade, mesmo porque podem ser superados com o apoio de professores experientes e da coordenação/supervisão pedagógicas, buscando todos amenizar o "choque com a realidade", vivido com sofrimento por inúmeros professores iniciantes. 


\section{PERCURSOS TRILHADOS}

O Programa de apoio aos professores iniciantes da Rede Municipal de Ensino de Poços de Caldas (PAPIN) foi submetido ao edital PAEX ${ }^{5}$, e desenvolvido em parceria com a Secretaria Municipal de Educação de Poços de Caldas.

Por meio de edital público foram selecionadas para participar do Programa 25 professoras que atuavam na rede municipal de ensino há, no máximo, 3 (três) anos, além de bolsistas do PIBID/UEMG - Subprojeto de Pedagogia (Poços de Caldas). O PAPIN foi executado nas dependências da UEMG/Poços de Caldas, entre os meses de agosto e dezembro de 2015.

Foram realizados, no total, 16 encontros em periodicidade semanal e totalizando 52 horas. A equipe responsável pela execução do projeto foi composta por 8 docentes da UEMG e 1 aluna egressa da instituição, além de 1 doutoranda da UFSCar e três analistas pedagógicas da Secretaria Municipal de Educação, que desenvolveram os seguintes temas:

- O início da docência: sobrevivência ou descoberta?

. A importância da reflexão sobre a docência

. O apoio ao professor/a iniciante: a função da supervisão/coordenação pedagógica

- Relações existentes (e possíveis) entre as famílias/docentes/escolas públicas

. Ampliando os olhares sobre as infâncias

. O desafio da inclusão no dia-a-dia escolar

. A indisciplina e a sala de aula

. Desmistificando temas: a sexualidade infantil

. A inserção das novas tecnologias nas salas de aula

. Linguagem e alfabetização

. Ações e estratégias de ensino em sala de aula

. Estudos sobre atividades administrativas na escola

. Pesquisas em educação

. A gestão da rede municipal de educação: limites e possibilidades

\footnotetext{
${ }^{5}$ Programa institucional de apoio à extensão, que auxilia docentes em projetos e ações extensionistas a partir da concessão de bolsas.
} 
Alguns dos temas mencionados foram sugeridos pelo grupo de alunas ao longo do desenvolvimento do programa, com base nas relações estabelecidas entre a teoria discutida e a docência vivenciada por elas nas unidades escolares.

Foram utilizadas técnicas de ensino como aulas expositivas e dialogadas, leituras compartilhadas, relatos de experiências, projeção de filmes/documentários e oficinas. Sistematicamente foram realizadas avaliações informais dos encontros (sobre as temáticas e metodologias abordadas), de forma a construir um programa que se adequasse às necessidades das participantes a partir de suas dificuldades e desafios no início da docência.

\section{CONSIDERAÇÕES FINAIS}

Ao término do programa, as participantes constataram que 0 acompanhamento pedagógico e profissional realizado possibilitou a reflexão sistemática sobre a realidade docente em que se encontravam nas unidades escolares - realidades diversas e muito complexas, como se apresentam as realidades da educação pública.

Para as participantes, os relatos de experiência e a discussão dos textos auxiliaram na busca de estratégias que superassem (ou minimizassem) as dificuldades no início da docência. Estas, conforme observado, se referem, basicamente, ao início da socialização profissional e a ausência de apoio pedagógico por parte dos supervisores pedagógicos e direções das unidades escolares (essas questões puderam ser discutidas diretamente com a gestora municipal de educação, que foi uma das docentes do programa).

Diferentemente do que tradicionalmente os estudos sobre o início da docência apontam, a indisciplina em sala de aula não foi apresentada como uma dificuldade ou desafio relevantes para as participantes, que consideraram a importância de se compreender as características da infância e juventudes contemporâneas para uma boa convivência entre professores e alunos na sala de aula, e, nesse sentido, nenhuma das participantes relatou qualquer dificuldade.

Os momentos de indisciplina de seus alunos foram, portanto, relatados como "previsíveis" dentro do universo da docência, cabendo a elas a criação e desenvolvimento de estratégias que minimizassem o impacto dessas situações. 
Como resultado imediato do projeto, foi criado um grupo de rede social que, através de contato diário entre as alunas participantes e a coordenação do Programa, proporciona, ainda em meados do corrente ano, a socialização de experiência e troca de saberes docentes, além de participação e reflexão cotidianas sobre o cenário educacional e político, seja local, estadual ou nacional.

Ao longo dos encontros, inúmeros foram os pedidos de professoras da Educação Básica da rede municipal de educação para participarem do PAPIN, e esse fato nos atentou à possibilidade continuidade do programa, em parceria com a Secretaria Municipal de Educação, seja na forma de sequencia do acompanhamento para as alunas dessa $1^{\underline{a}}$ turma, seja como a abertura de uma nova turma, buscando plantar as sementes para a institucionalização do Programa como uma ação permanente do poder público.

Considerando que as ações e estratégias de ensino compartilhadas pelas alunas e apresentadas durante os encontros semanais foram, inúmeras delas, desenvolvidas com seus alunos em sala de aula - entende-se que aproximadamente 24 turmas, totalizando cerca de 500 crianças foram indiretamente impactadas pelas atividades desenvolvidas no PAPIN.

Entende-se que ações de apoio aos professores iniciantes são revestidas de importância capital para sua permanência na docência e seu desenvolvimento profissional. Programas de inserção docente, incipientes no Brasil, são fundamentais para que não haja o abandono da docência, haja vista os cenários difíceis e complexos nos quais se inserem no início da docência.

O PAPIN propiciou apoio pedagógico e profissional para a inserção docente, desenvolvendo ação de formação continuada para professoras que são, em boa parte, egressas da UEMG. Neste sentido, houve uma intensificação na interlocução entre universidade e docentes de educação básica, também contribuindo para estreitar e aprofundar a difícil relação entre saberes docentes discutidos na universidade e práticas docentes vivenciadas em escolas da educação básica.

Finalizando, o projeto foi premiado pela UEMG, e a quantia recebida foi destinada à reprodução de DVDs contendo o material bibliográfico e eletrônico apresentados e discutidos nos encontros, material esse repassado e compartilhado com outras docentes da educação básica do município. 


\section{REFERÊNCIAS}

CAVACO, M.H. Ofício de Professor. O tempo das mudanças. In: NÓVOA, A. Profissão Professor. Porto: Porto Editora, 2000, p. 155-191.

FONTANA, R. C. Trabalho e subjetividade: Nos rituais da iniciação, a constituição do ser professora. Cadernos Cedes, Campinas, ano XX, n.50, abril/2000. p.103-119. Disponível em: <http://www.scielo.br/pdf/ccedes/v20n50/a08v2050.pdf>. Acesso em: 20 jul. 2011.

GATTI, B. A.; BARReto, E. S. S.; ANDRÉ, M. D. A. Políticas docentes no Brasil: um estado da arte. Brasília: UNESCO, 2011. Disponível em <http://unesdoc.unesco.org/images/0021/002121/212183por.pdf>. Acesso em: 15 jul. 2012.

GUARNIERI, M. R.; GIOVANNI, L. M. Resultados de pesquisas sobre professores iniciantes e as tendências atuais de reforma da formação de professores: distância, ambigüidades e tensões. In: II Congreso Internacional sobre profesorado principiante e inserción profesional a la docencia, 2010, Buenos Aires. Comunicaciones.... Disponível em: <http://cedoc.infd.edu.ar/noveles/principiantes/4/Simposio\%20Brasil\%20\%20INV\%20-\%204\%20-\%20LMGIOVANNI_e_MRGUARNIERI.pdf>. Acesso em: 18 dez. 2012.

HARGREAVES, A. Os professores em tempos de mudança. O trabalho e a cultura dos professores na idade pós-moderna. Lisboa, Portugal: Mac Graw-Hill, 2001.

KNOBLAUCH, A. Aprendendo a ser professora: um estudo sobre a socialização profissional de professores iniciantes no município de Curitiba. 2008. $146 \mathrm{f}$. Tese (Doutorado em Educação) São Paulo: Pontifícia Universidade Católica de São Paulo, 2008. Disponível em: $<$ http://www.sapientia.pucsp.br/tde_busca/arquivo.php?codArquivo=6064> Acesso em: 20 out. 2012.

MARCELO GARCÍA, C. Formação de professores. Para uma mudança educativa. Porto: Porto Editora, 1999b.

Políticas de inserción en la docencia: de eslabón perdido a puente para el desarollo profesional docente. Programa de Promoción de la Reforma Educativa en América Latina y el Caribe (PREAL). 2011. Serie Documentos n.52. Disponível em: <http://www.preal.org/Archivos/Preal\%20Publicaciones/PREAL\%20Documentos/PR EALDOC52.pdf>. Acesso em: 24 junho 2014.

MIZUKAMI, M. G. N. Docência, Trajetórias Pessoais e Desenvolvimento Profissional. In: REALI, A. M. M. R; MIZUKAMI, M. G. N. (org.) Formação de Professores: Tendências atuais. São Carlos, SP: EdUFSCar, 1996. p. 59-91. 
SARASON, S.B. The Culture of the School and the Problem of Change. Boston: Allyn and Bacon. 1982. LIMA, J. Á. As culturas colaborativas nas escolas estruturas, processos e conteúdos. Porto: Porto Editora, 2003

VAILLANT, D. Políticas de inserción a la docência em America latina: La deuda pendiente. In: Profesorado. Revista de curriculum y formación del profesorado. Universidad de Granada, España. v.13, n.1, 2009. Disponível em: <http://www.ugr.es/ recfpro/rev131ART2.pdf>. Acesso em: 27 jan. 2013.

VEENMAN, S. Perceived problems of beginning teachers. Review of Educational Research, n. 54. p. 143-178, 1984.

VEENMAN, S.; DE LAAT, H.; STARING, C.. Coaching Beginning Teachers. European Conference on Educational Research. Ljubljana, Slovenia, September 17-20/1998. p. 01-19. 